International Review of Research in Open and Distributed Learning Volume 17, Number 3

April - 2016

\title{
Factors Affecting Students' Behavioral Intention to Use LMS at a Turkish Post-Secondary Vocational School
}

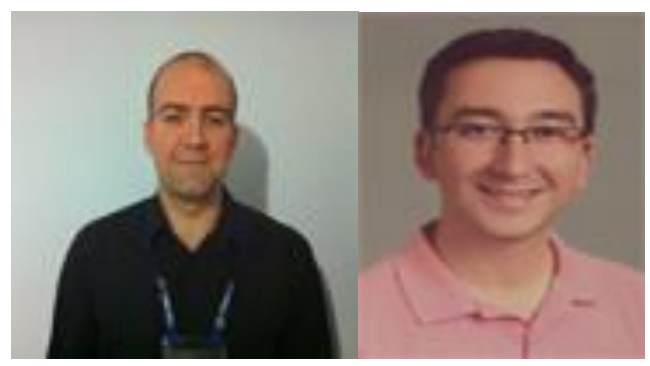

Harun Cigdem ${ }^{1}$ and Mustafa Ozturk ${ }^{2}$

${ }^{1}$ Turkish Land Forces Non-Commissioned Officer Vocational College; ${ }^{2 H a c e t t e p e ~ U n i v e r s i t y ~ S c h o o l ~ o f ~ F o r e i g n ~ L a n g u a g e s, ~}$ Turkey

\begin{abstract}
There is a substantial increase in the use of learning management systems (LMSs) to support teaching and learning activities in higher education institutions. Despite their benefits, students use them to a limited extend due to a number of factors influencing behaviors. This study executed a three-tier use model to examine the predictors of students' behavioral intention to use LMSs at a two-year postsecondary military school in Turkey, and the participants consisted of 155 students. The data were collected through an online questionnaire and analyzed through Pearson correlation coefficients and linear regression analyses. Results showed that multimedia instruction had a direct influence on perceived usefulness and perceived ease of use, while interactivity had a direct influence only on perceived satisfaction. Perceived satisfaction was also affected by perceived usefulness and perceived ease of use. Perceived ease of use exerted a direct influence on perceived usefulness, as well. Moreover, perceived usefulness had a great influence on behavioral intention to use LMSs. As a final point, self-efficacy did not take a position in the model due to its insignificant relationships with the other constructs. It is suggested that an increase in the multimedia features and interactivity of the system could lead to higher perceived usefulness and ease of use among learners, and both factors add to learners' perceived satisfaction which in turn increases their engagement.
\end{abstract}

Keywords: Behavioral intention; blended learning; interactivity; LMS; 3-TUM 


\section{Introduction}

As a fundamental area of computer science and education, e-learning practices, which stand for learning processes that are Web-based, have started to dominate the majority of the applications. Since e-learning provides learners with educational practices available anywhere at anytime, which is not possible in traditional classroom settings, it appears as a more noteworthy method (Cigdem, 2015). E-learning programs have been used by educational institutions to serve three main purposes: improving their educational systems; meeting their students' needs; and preparing the new generation for challenges of tomorrow's world (Hernandez, Montaner, Sese, \& Urquizu, 2011). Today, one of the most widespread innovations used in e-learning practices is learning management systems (LMSs). There is a substantial increase in the use of the LMSs over the Internet to support teaching and learning activities in higher education institutions (Álvarez, Martín, Fernández-Castro, \& Urretavizcaya, 2013; Cigdem \& Topcu, 2013; Damnjanovic, Jednak \& Mijatovic, 2013; Dutta, Roy, \& Seetharaman, 2013; Islam, 2013). The LMSs comprise a broad mixture of features that are possibly utilized to support both distance learning and conventional methods (Islam, 2013). As in many other instructional technologies, the major purpose of using the LMSs is to reach the intended learning outcomes of a course or training as well as to increase students' engagement with distance learning, because they have the potential to offer new learning and teaching methods that meet diverse educational needs in diverse settings. With this intention, the Turkish Land Forces Non-Commissioned Officer College has been offering blended courses since the 2012-2013 academic year and is willing to take full advantage of the LMS through MOODLE in all academic programs within the institution. Although a variety of names or labels are attributed the LMS such as platforms, portals, content management systems, and so on, the current institution named the system Portal.

Despite the substantial growth of such systems in recent years, educational institutions are still faced with a number of challenges in relation to e-learning practices. Especially, delivery and acceptance of elearning programs are among the diffculties that a lot of universities frequently experience (Park, 2009). Lack of interest on the side of the faculty or teaching staff in using the LMSs in their practices are claimed as a challenge (Stantchev, Colomo-Palacios, Soto-Acosta, \& Misra, 2014). Some other studies state that a great number of students are not satisfied with e-learning programs they are offered (Bouhnik \& Marcus, 2006; Liaw, 2008). According to Selim (2007), there are four critical dimensions influencing the effectiveness of an e-learning application: instructor characteristics, student characteristics, technology, and support. As Campbell and Swift (2006) further clarify, not only instructors but also students are to reconsider and change their attitudes, beliefs, behaviors, perspectives, and habits to be able to adapt to the use of technology efficiently. In this sense, Liaw (2004) highlights three key considerations: learner characteristics, instructional structure, and interactions that serve to assist the efficient adaptation of the institutions and the instructors to e-learning. All the aforementioned propositions reveal that due consideration should be given to understanding learners' perceptions on and behavioral intention to use the LMSs when developing promising systems. The latter one, which refers to perceived likelihood and willingness to be engaged in an action, has been the focus of the educational research in many contexts rapidly as a result of the increase in the use of the LMS by contemporary educational institutions. In this 
line, identifying critical factors related to students' behavioral intention to use the LMSs is apt to continue as a significant issue.

\section{Theoretical Framework}

The previous literature presents several models that could explain perceptions on the acceptance of or behavioral intentions to use a new technology. A remarkable model in this context was proposed by Liaw (2007) and called the three-tier use model (3-TUM). This model was characterized to explore the attitudes of the users towards information technologies at three levels: (a) individual experiences and system quality; (b) affective and cognitive reactions; and (c) behavioral intentions (see Figure 1).

\begin{tabular}{|l|l|l|}
\hline $\begin{array}{l}\text { The first tier: the tier } \\
\text { of individual experience } \\
\text { and system quality }\end{array}$ & $\longrightarrow \begin{array}{l}\text { The second tier: } \\
\text { the affective and } \\
\text { cognitive tier }\end{array}$
\end{tabular}$\longrightarrow$\begin{tabular}{l}
$\begin{array}{l}\text { The third tier: } \\
\text { behavioral } \\
\text { intention tier }\end{array}$ \\
\hline
\end{tabular}

Figure 1. The three-tier use model (3-TUM) (Liaw, 2007).

As shown in Figure 1, the model is conceptualized in a way that the first tier, individual experience and system quality, could positively influence the second tier, affective and cognitive experiences. In a similar vein, the second tier tends to influence positively the third one which is the behavioral intention tier. In the end, the behavioral intention tier focuses on how to predict learners' behaviors to employ the intended technology for certain purposes through the research model. The conceptual foundation that the current study was built upon is the 3-TUM of Liaw (2007). However, other theoretical backgrounds such as the social-cognitive theory of Bandura (1977); the theory of planned behavior by Ajzen (1991); and the technology acceptance model (TAM) of Davis, Bagozzi and Warshaw (1989) and TAM-2 (Venkatesh \& Davis, 2000) have contributed to the model and enabled the model to reach an integrated conceptual framework.

On the basis of the findings and propositions suggested in the previous literature, the current study intends to execute the 3-TUM to understand the relationships between the military vocational college students' behavioral intention to use the Portal and the selected factors such as self-efficacy, multimedia instruction, interactivity, perceived usefulness, perceived satisfaction, and perceived ease of use (see Figure 2). 


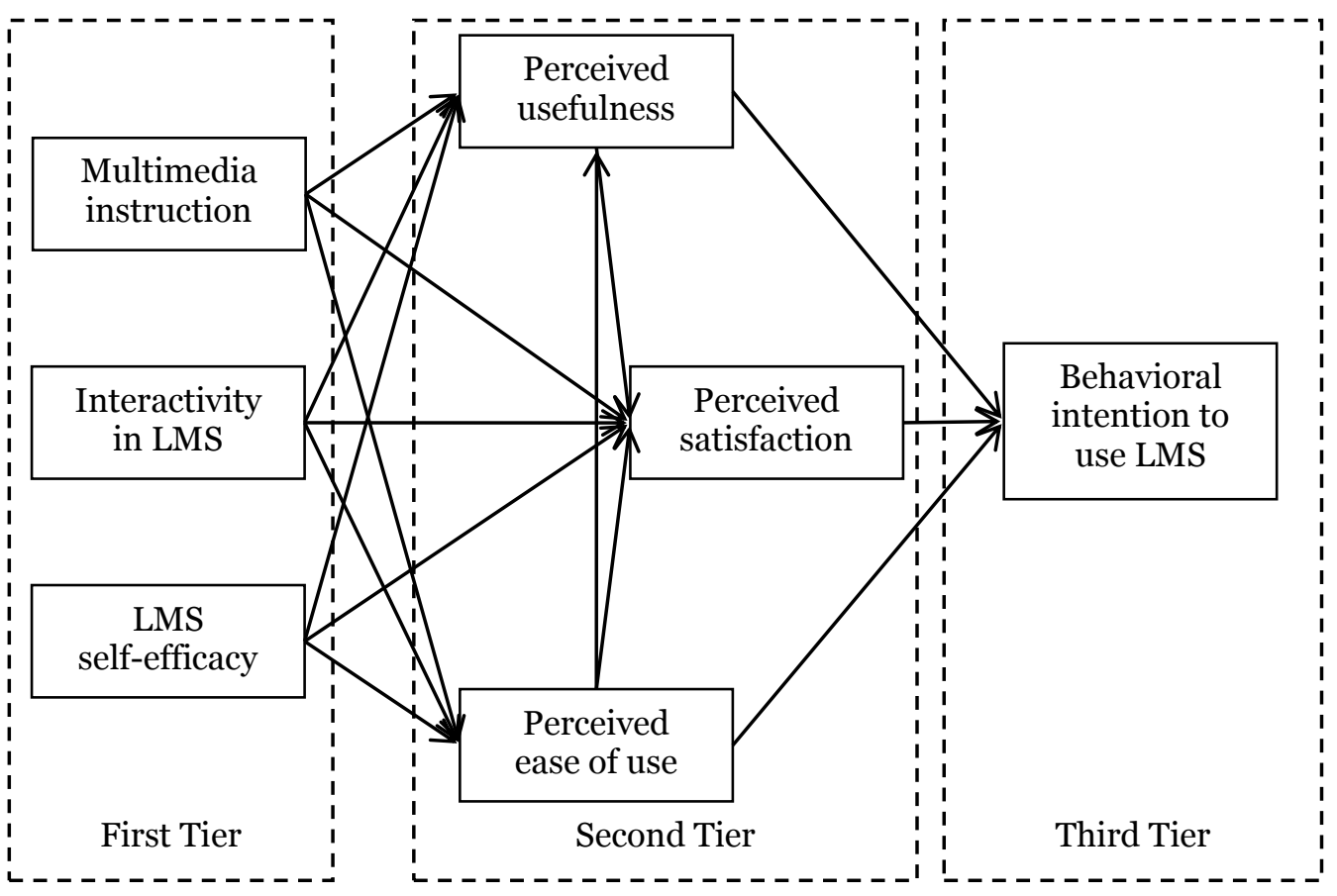

Figure 2. Theoretical framework of the study.

Self-efficacy is defined as "people's judgments of their capabilities to organize and execute courses of action required attaining designated types of performances" (Bandura 1986, p. 391). The concept of selfefficacy is considered to be one of the variables in the first tier of the 3-TUM and to have a strong influence on the use of a system, owing to its effects on perceived usefulness and perceived ease of use (Venkatesh \& Davis, 1996).

Multimedia lectures as a means of distance learning or as a supplement to conventional in-class learning have been around for several decades. With the development of the information technologies and the elimination of the barriers to video production, using multimedia in education has increased. Especially through video lectures, students are offered a rich learning experience, because video lectures have the potential to increase student retention and achievement in distance and blended learning environments (Geri, 2011). Besides, they might help the students who are not able to attend the courses regularly (Wieling \& Hofman, 2010). Presenting the course materials through multimedia seems to have positive effects on learners' satisfaction with the learning environment, which is likely to promote learners' participation in learning processes (Liaw, 2008). Therefore, multimedia instruction is considered to be another significant factor in learners' satisfaction with the Portal and thus distance learning.

As another key element of e-learning practices, interactivity stands for the interaction between the learners and the system's sources, the communication between the instructor and the learners, as well as the collaboration among the learners supported by the system under use. The interactivity is an important feature in all contemporary learning environments, regardless of the instructional methods or technologies used (Moore \& Kearsley, 1996). The interactivity between students and online resources is 
enhanced by using appropriate technologies and pedagogies efficiently. The interactivity within the LMS enables learners to explore and play with the course materials (Michailidou \& Economides, 2003) and therefore becomes as a decisive element for improving students' positive feelings such as perceived satisfaction (Yukselturk \& Yildirim, 2008) and perceived usefulness (Liaw \& Huang, 2007). The interactivity within the LMS is claimed to affect learners' perceived satisfaction (Liaw, 2008; Sahin \& Shelley, 2008; Šumak, Heričko, \& Pušnik, 2011; Sun, Tsai, Finger, Chen, \& Yeh, 2008) and use (Damnjanovic et al., 2013; Pituch \& Lee, 2006). All these points justify that a system's interactivity is expected to be a significant dimension that possibly affects the learners' adoption or rejection of the system. This feature of the system was rarely offered to the students in previous applications; hence it is though to increase the effectiveness of the Portal.

Perceived satisfaction, which is frequently used to evaluate a system's success or failure, is described as one's perception of information systems and the level of comfort while practicing those (Liaw \& Huang, 2013). In an e-learning environment, perceived satisfaction appears as an important indicator of the effectiveness of the instructional methods implemented in the online component of the system, and thus it could emerge as a barrier against the successful implementation of the system (Akkoyunlu \& Soylu, 2008; Melton, Graf, \& Chopak-Foss, 2009; Paechter, Maier, \& Macher, 2010). Several studies reveal that perceived usefulness positively predicts learners' satisfaction with e-learning (Cigdem \& Topcu, 2013; Johnson, Hornik, \& Salas, 2008; Liaw, 2008) and perceived satisfaction together with perceived usefulness directly affects learners' behavioral intention to use e-learning systems (Damnjanovic et al., 2013; Lee, Cheung \& Chen, 2005; Sahin \& Shelley, 2008).

Perceived ease of use is defined by Davis et al. (1989) as users' perceptions on the ease of adopting a system. In this context, as the level of perceived ease of use regarding an e-learning system increases, the acceptance and use of that system by the participants is most likely to increase (Teo, 2012; Teo, Lee \& Chai, 2008). In the TAM, attitude towards usage as well as the constructs like perceived usefulness and perceived ease of use is set to influence behavioral intention. While perceived ease of use exerts a direct impact on perceived usefulness, perceived usefulness together with perceived ease of use influences attitudes toward usage (Teo, 2011). In this sense, if users perceive that a system is easy to use, they tend to see the system as simple and satisfactory (Sun et al., 2008). Consequently, the users are expected to join in, use more, and remain longer in the system, for the reason that participants' acceptance of and use of a Web-based learning system is affected by their perceived ease of use (Zhang, Zhao, \& Tan, 2008). Perceived ease of use is claimed to have a direct impact on perceived usefulness but perceived usefulness is not claimed to have any affects on perceived ease of use (Davis et al., 1989).

Perceived usefulness, which is described as "the level that a person thinks using a certain system would enhance his/her job performance within an organizational content" (Davis, 1989, p. 320), is one of the major factors directly influencing the behavioral intention to use a technology (Cigdem \& Topcu, 2015; Sun et al., 2008; Venkatesh \& Morris, 2000). It is essential to consider the two key factors, which are envrionmental characteristics and individual learner characteristics, when investigating perceived 
usefulness of an e-learning environment (Bouhnik \& Marcus, 2006; Liaw \& Huang, 2007; Motiwalla, 2007; Šumak et al., 2011).

Behavioral intention is defined as the degree to which a person has formulated conscious plans to perform or not to perform some specified future behavior (Warshaw \& Davis, 1985), and there might appear a lot of factors possibly influencing learners' behavioral intention to use the LMS in their learning processes.

Building on the scheme discussed so far, understanding the students' behavioral intention to use the Portal appears as a critical issue not only to enhance the use of the Portal, but also to demonstrate their possible effects. According to Yi and Hwang (2003), self-efficacy operates at two distinct levels: (a) the general computing level and (b) the specific application level, which could be exemplified with the utilization of the LMS. For the current study aiming to exhibit the importance of the LMS, the self-efficacy concept was set to represent the students' judgments of their ability to perform in the LMS and confidence in finding information and communicating with an instructor within the LMS. In this scope, it is assumed that the students who show distrust in their capabilities might perceive that the LMS is too complex to operate and prefer to avoid using the system. As for the multimedia instruction, videos related to office software such as word processing and spreadsheets were produced by the lecturer, and Macromedia Captivate and Camtasia Studio applications were used for the production of the videos through screen capturing. All the videos, presentations, and lecture notes were uploaded to the system to enrich the multimedia feature of the instruction. In the design, the interactivity was ensured through the feedback provided on the assignments and works of the students by the instructors as well as the learners' engagement with the materials in the system. At this point, multimedia instruction and interactivity are regarded as the environmental characteristics of the current design and learner characteristics are considered to be based on their self-efficacy.

Everything considered, this study, based on the conceptual model proposed by Liaw (2007), aimed to examine the predictors of the learners' behavioral intention to use the Portal in a computer literacy course at a post secondary military vocational school from the constructs of perceived self-efficacy, multimedia instruction, interactivity, perceived satisfaction, perceived ease of use, and perceived usefulness. With the help of this study, researchers and providers of the LMS could have a comprehensive understanding about the learners' perceptions on and reactions to the use of LMS and therefore design and deliver better systems that can involve more users and result in more efficient learner outcomes. With the development of computer technologies and learning management systems, constructing multimedia lectures have been easier and communication tools between instructors and learners have increased. Therefore, it has become crucial to study the infleunce of multimedia and interactivity within a system on learners' behavioral intention to use LMSs. Another significance of the study is about the research context. Military schools have been a unique teaching setting in terms of the limited interaction between students and instructors due to a number of norms. For that reason, utilizing the LMS in such settings is thought to be a valuable opportunity to motivate learners and increase their engagement. As little research has been done at post secondary vocational schools and military schools, through this investigation, this study intends to contribute to the literature and provide samples for similar educational settings. 
The specific research questions that the study aimed to answer were as fallows:

- Can perceived ease of use be predicted from learners' self-efficacy and multimedia and interactivity features of the LMS?

- Can perceived usefulness be predicted from learners' self-efficacy and multimedia and interactivity features of the LMS and perceived ease of use?

- Can perceived satisfaction be predicted from learners' self-efficacy, multimedia and interactivity features of the LMS, perceived ease of use and perceived usefulness?

- Can learners' behavioral intention to use the LMS be predicted from perceived satisfaction, perceived ease of use and perceived usefulness?

\section{Method}

\section{Research Context and Participants}

This study was carried out at a two-year post-secondary military school of Balikesir province in Turkey. Students are accepted to this school based on multi-step selection procedures consisting of a national university entrance examination, a physical test conducted by the Turkish Land Forces, and interviews with the commanders at the school. The candidates are offered vocational and technical training beside military preparation in order to be an NCO (non-commissioned military officer).

Since one of the researchers works as an instructor at the college, the convenient sampling was used to select the participant users, and the designed Portal was used in that researcher's course. The participants consisted of 155 military school students taking Computer Literacy during the first semester of the 20142015 academic year. As the research context was military school, all the participants were male students living on the college campus, which makes the research a unique study and at the same time exerts a limitation. The participants' age ranged from 18 to 23 with an average of $19(S D=1.09)$. Among the participants, there were students majoring in the Department of Automotive Technologies $(n=61)$ and the Department of Electronics and Communication Technologies $(n=94)$. Most of the participants $(n=$ 126) were graduates of vocational high schools and the rest $(n=29)$ of general high schools. As for the prior experience on e-learning, most of the participants $(n=120)$ reported that they did not have any elearning experiences before, whereas the rest had $(n=35)$.

\section{Portal}

The study was conducted in the context of the course titled Computer Literacy, which was compulsory for the Department of Automotive Technologies and the Department of Electronics and Communication Technologies. The course content was offered in a blended format for a 15-week semester as well as through 100-minute face-to-face lectures in each week. In each face-to-face session, students were 
presented with the pre-planned content of the week. The course content included almost all office specialties and covered a vast body of office software knowledge, which made the course to be completed in a limited time by the participants. This fact was the rationale behind the course's being offered in a blended format. Completing the face-to-face session, the participant students were asked to create office software projects in computer labs. A short summary and feedback related to common mistakes were provided at the end of each face-to-face session. Students who could not participate in or had difficulty in understanding the face-to-face lectures were expected to log onto the course Web site individually through the intranet.

Within the online part of the course environment, the participants were also provided with the lecture notes, presentations, sample projects, learning activities, online assignments, and videos over the intranet on the Portal. Through this feature, students were able to review the videos, upload assignments, and send messages to the instructor anywhere and anytime in the college campus. Portal gave learners the opportunity to control what subject they would like to work on. Screenshot examples of Portal and the video simulations could be seen in Figure 3 and Figure 4.

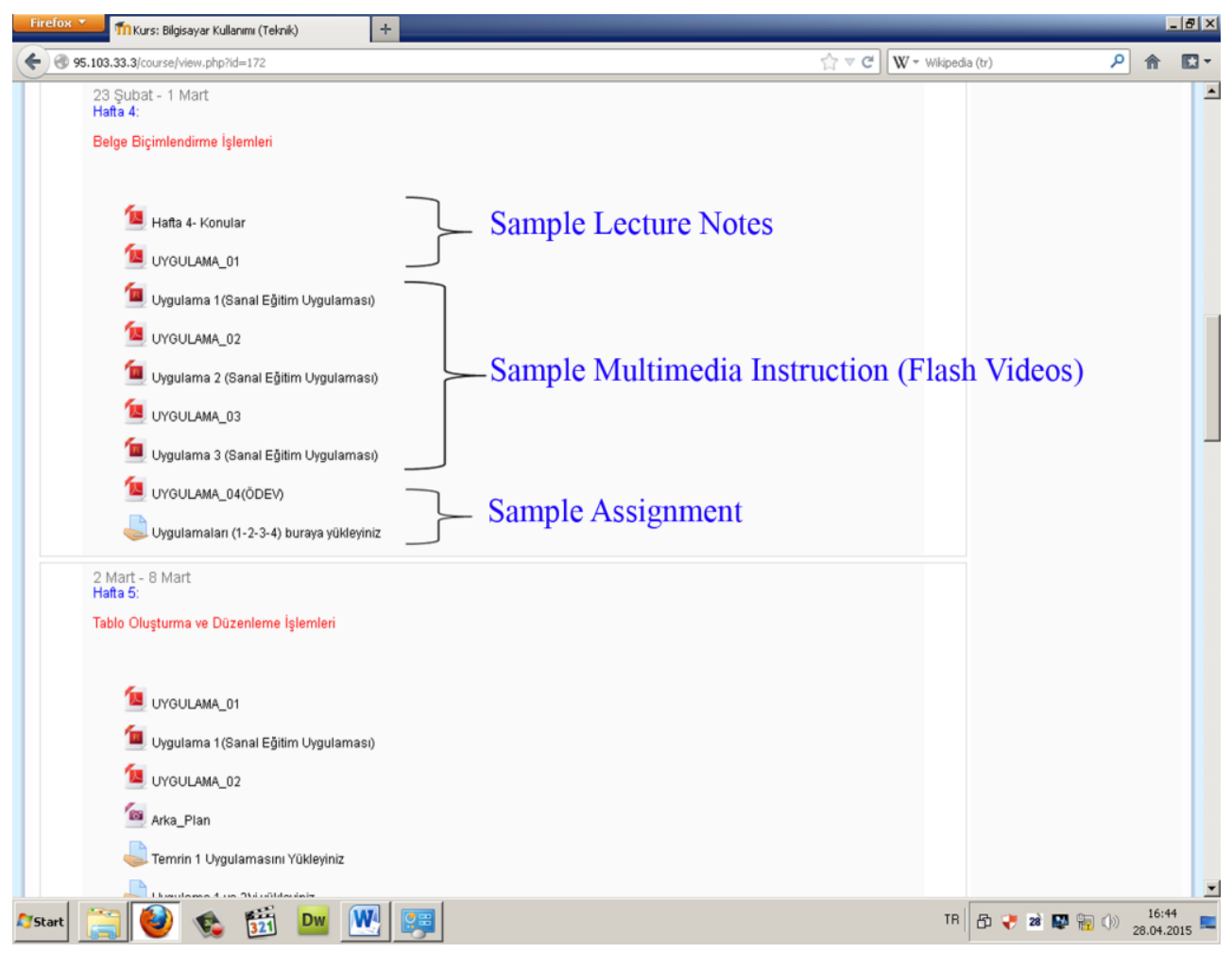

Figure 3. A screenshot of the Computer Literacy Web site. 


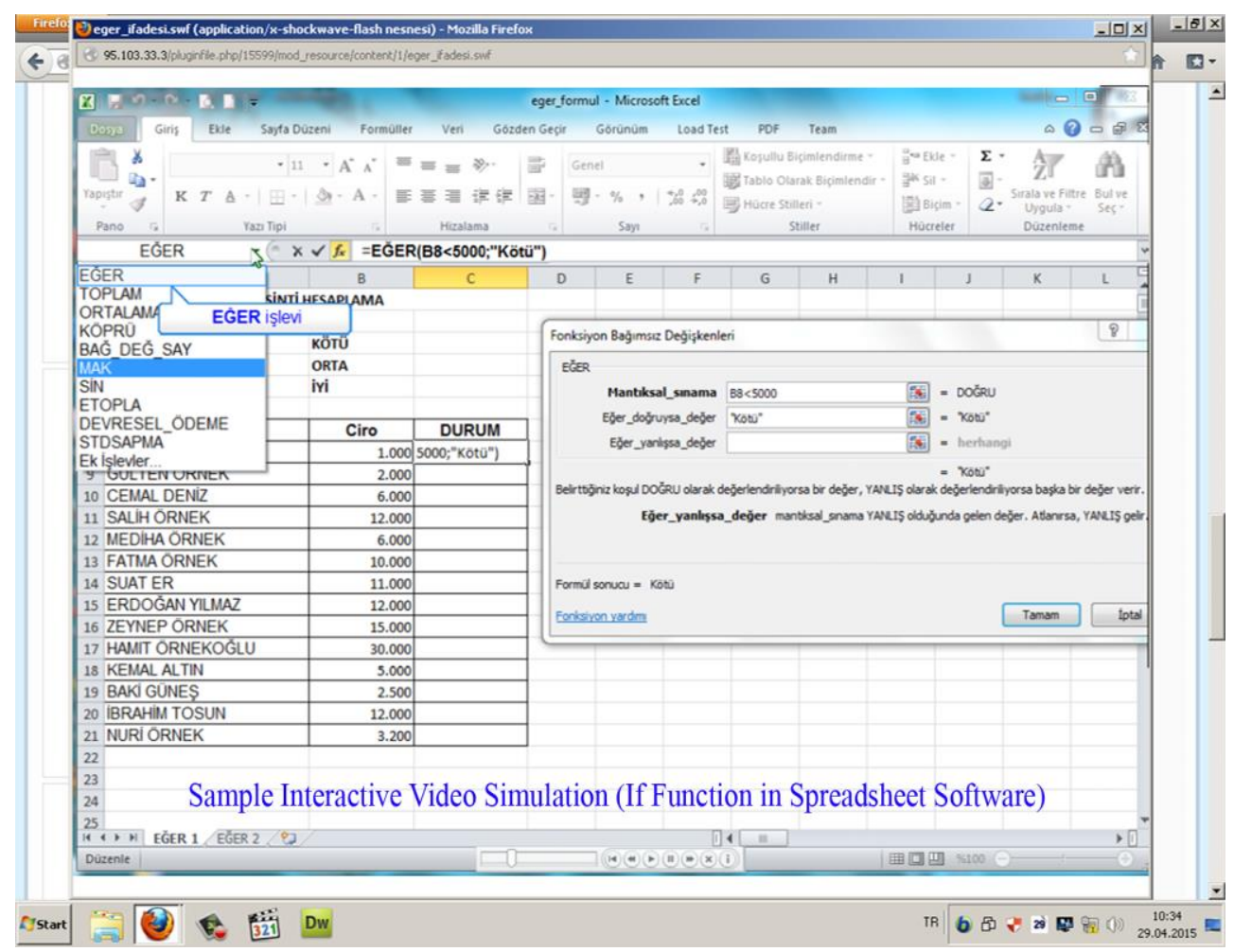

Figure 4. A screenshot of interactive video simulation captured by Adobe Captivate.

\section{Data Collection Instrument}

The data were collected through an online questionnaire, which was built on the propositions of Davis (1989) and Liaw (2008). The questionnaire included 21 five-point Likert-type items with a response scale from 5 (strongly agree) to 1 (strongly disagree) and an additional section inquiring the participants' demographical characteristics. The underlying structure of the questionnaire composed of seven factors representing learners' perceived self efficacy, multimedia instruction, interactivity of the Portal, learners' perceived satisfaction, perceived ease of use and perceived usefulness of the Portal, and learners' behavioral intention to use the Portal. Items placed in each subscale are presented in Table 1.

Table 1

Distribution of Survey Items to Factor Structure

\begin{tabular}{cccc}
\hline Factor & Item & Mean & $S D$ \\
\hline LMS self-efficacy* & 4.10 & .486 \\
I1 $\quad$ I feel confident using Portal. & 4.24 & .593 \\
I2 & I feel confident operating functions of Portal. & 3.92 & .609 \\
I3 $\quad$ I feel confident using contents of Portal. & 4.15 & .560 \\
Multimedia instruction* & 4.40 & .526 \\
I4 I like to use video media instruction in Portal & 4.27 & .595 \\
I5 $\quad$ I like to use multimedia instruction in Portal & 4.45 & .636 \\
I6 $\quad$ I like to use presentations/slides in Portal & 4.48 & .585 \\
Perceived satisfaction* & 4.20 & .443 \\
\hline
\end{tabular}




\begin{tabular}{clcc}
\hline I7 & I am satisfied with using Portal as a learning assisted tool & 4.20 & .597 \\
I8 & I am satisfied with using functions of Portal & 4.34 & .584 \\
I9 & I am satisfied with multimedia instruction in Portal & 4.33 & .548 \\
I10 & I am satisfied with interactivity in Portal & 3.94 & .600 \\
Interactivity in Portal* & 4.13 & .503 \\
I11 $\quad$ I would like to share my e-learning experience & 4.08 & .683 \\
I12 & I believe Portal can assist teacher-learner interaction & 4.28 & .587 \\
I13 I believe Portal system can assist learner-learner interaction & 4.03 & .608 \\
Perceived usefulness** & 4.48 & .475 \\
I14 $\quad$ Using Portal gives me greater control over my work & 4.54 & .595 \\
I15 $\quad$ Using Portal improves my performance & 4.51 & .585 \\
I16 $\quad$ Using Portal makes it easier to do my job & 4.39 & .608 \\
I17 I believe Portal contents are useful & 4.49 & .562 \\
Perceived ease of use** & 4.41 & .453 \\
I18 $\quad$ Learning to operate Portal system would be easy for me & 4.49 & .563 \\
I19 I would find it easy to get Portal to do what I want it to do & 4.40 & .565 \\
I20 I would find the system easy to use & 4.34 & .540 \\
Behavioral intention** & 4.44 & .452 \\
I21 I intend to use Portal to assist my learning & 4.41 & .579 \\
I22 $\quad$ I intend to use functions of Portal to assist my learning & 4.48 & .574 \\
I23 I intend to use Portal as an autonomous learning tool & 4.33 & .582 \\
I24 $\quad$ I would like to see Portal functions implemented further in departmental & 4.53 & .561 \\
\hline
\end{tabular}

Note. $S D=$ standard deviation of the mean. *Items were adapted from Liaw (2008, p.871). **Items were adapted from Davis (1989, p.324).

In order to determine the internal consistency of the questionnaire and see whether the items that were summed to create each factor formed a reliable scale, Cronbach's alpha was computed for both the overall questionnaire and the subscales within the questionnaire. The alpha for the subscales ranged from .72 to .84 , and the overall alpha was .92. All the values revealed reasonable levels of reliability (see Table 2 for the values of the reliability analyses).

Table 2

Results of Reliability Analyses

\begin{tabular}{lcc}
\hline Subscale & Items & Cronbach's Alpha \\
\hline LMS self-efficacy & 3 & .769 \\
Multimedia instruction & 3 & .837 \\
Interactivity in Portal & 3 & .723 \\
Perceived ease of use & 3 & .750 \\
Perceived usefulness & 4 & .825 \\
Perceived satisfaction & 4 & .757 \\
Behavioral intention & 4 & .796 \\
\hline Total & 24 & .920 \\
\hline
\end{tabular}

\section{Data Analysis}


The data obtained from the responses in the questionnaire were analyzed through inferential statistics. In order to see the relationships and correlations between the constructs within the research design, Pearson correlation coefficients and linear regression analyses were performed to examine the points addressed in the research questions.

\section{Results}

In advance of the regression analyses, multicollinearity assumption was checked in order to see whether there was a multicollinearity problem among the predictor variables involved in the analyses. As multicollinearity might occur with a high level of correlation $\left(r_{\mathrm{xy}}>.90\right)$ between two or more variables, the predictors with a value of .90 or higher were determined through an examination of item-item matrix (Field, 2009; Kline, 2011; Tabachnick \& Fidell, 2007). With the purpose of examining the correlations among all the factors represented in the scale, Pearson correlation coefficients were performed. In order to control the Type I error across the correlations, a $p$ value of less than .01 was required for significance. Accordingly, all the seven factors were significantly correlated with each other, except for the one between self efficacy and behavioral intention. As demonstrated in Table 3, all the correlations were all less than .80 and there was not any high correlations $\left(r_{\mathrm{xy}}>.90\right)$ among the predictors. As a result, it was assumed that there was no multicollinearity problem among the predictor variables of the regression analyses. The strongest correlations indicated that the multimedia features of the system tended to increase participant learners' perceptions in relation to the ease of use and the usefulness of the system. The weakest correlations were between the self-efficacy of the learners and the other constructs (see Table 3).

Table 3

Pearson Correlations Among the Factors

\begin{tabular}{|c|c|c|c|c|c|c|}
\hline Factors & 2 & 3 & 4 & 5 & 6 & 7 \\
\hline 1. Self-efficacy & $.298^{*}$ & $.642^{*}$ & $.224^{*}$ & $.310^{*}$ & $.428^{*}$ & .201 \\
\hline 2. Multimedia instruction & & $376^{*}$ & $.756^{*}$ & $.785^{*}$ & $.369^{*}$ & $.541^{*}$ \\
\hline 3. Interactivity in Portal & & & $.300^{*}$ & $.376^{*}$ & $.574^{*}$ & $.218^{*}$ \\
\hline 4. Perceived ease of use & & & & $.683^{*}$ & $.414^{*}$ & $.497^{*}$ \\
\hline 5. Perceived usefulness & & & & & $.514^{*}$ & $.692^{*}$ \\
\hline 6. Perceived satisfaction & & & & & & $.436^{*}$ \\
\hline 7. Behavioral intention & & & & & & \\
\hline
\end{tabular}

Note. ${ }^{*}$ Correlation is significant at the .01 level (2-tailed).

As for the first research question inquiring whether perceived ease of use could be predicted by the constructs of learners' self-efficacy, multimedia instruction, and interactivity feature of the system, the regression analysis indicated a significant result, $R^{2}=.572, F(3,151)=67.221, p<.001$, only in that multimedia instruction within the system positively influenced the scores regarding perceived ease of use (see Table 4).

Table 4 
Self-Efficacy, Multimedia Instruction, and Interactivity as Predictors of Perceived Ease of Use

\begin{tabular}{lccccc}
\hline Variables & $B$ & $S E$ & $\beta$ & $t$ & $p$ \\
\hline LMS self-efficacy & -.016 & .065 & -.017 & -.249 & .804 \\
Multimedia instruction & .647 & .050 & .750 & 13.016 & .000 \\
Interactivity in Portal & .026 & .065 & .029 & .398 & .691 \\
\hline
\end{tabular}

Note. $\mathrm{B}=$ unstandardized coefficients, $\mathrm{SE}=$ standard error of the estimate, $\beta=$ standardized coefficients

In a further analysis, learners' self-efficacy, multimedia instruction, interactivity feature of the system, and perceived ease of use were checked to see whether they predict the construct of perceived usefulness. It revealed a significant result, $R^{2}=.643, F(4,150)=67.521, p<.001$, which turned out that multimedia instruction and perceived ease of use exerted positively significant affects on the scores pertaining to perceived usefulness of the system (see Table 5).

Table 5

Self-Efficacy, Multimedia Instruction, Interactivity, and Perceived Ease of Use as Predictors of Perceived Usefulness

\begin{tabular}{lccccc}
\hline Variables & $B$ & $S E$ & $\beta$ & $t$ & $p$ \\
\hline LMS self-efficacy & .048 & .063 & .049 & .763 & .447 \\
Multimedia instruction & .535 & .070 & .592 & 7.690 & .000 \\
Interactivity in Portal & .057 & .062 & .060 & .915 & .361 \\
Perceived ease of use & .216 & .078 & .206 & 2.767 & .006 \\
\hline
\end{tabular}

Note. $\mathrm{B}=$ unstandardized coefficients, $\mathrm{SE}=$ standard error of the estimate, $\beta=$ standardized coefficients

Regarding the third research question which is related to the perceived satisfaction's being predicted by the constructs of self-efficacy, multimedia instruction, interactivity, perceived ease of use, and perceived usefulness, the regression analysis also put forward a significant result, $R^{2}=.466, F(5,149)=25.975, p<$ .001. Accordingly, it was seen that interactivity, perceived ease of use, and perceived usefulness tended to exert significantly positive influences on the perceived satisfaction scores. On the other hand, multimedia instruction had a negative effect on perceived satisfaction (see Table 6).

Table 6

Self-Efficacy, Multimedia Instruction, Interactivity, Perceived Ease of Use, and Perceived Usefulness as Predictors of Perceived Satisfaction

\begin{tabular}{lccccc}
\hline Variable & $B$ & $S E$ & $\beta$ & $t$ & $p$ \\
\hline LMS self-efficacy & .062 & .072 & .068 & .867 & .387 \\
Multimedia instruction & -.258 & .094 & -.306 & -2.744 & .007 \\
Interactivity in Portal & .370 & .071 & .420 & 5.187 & .000 \\
Perceived ease of use & .204 & .092 & .209 & 2.223 & .028 \\
Perceived usefulness & .403 & .093 & .433 & 4.317 & .000 \\
\hline
\end{tabular}

Note. $\mathrm{B}=$ unstandardized coefficients, $\mathrm{SE}=$ standard error of the estimate, $\beta$ =standardized coefficients 
The final analysis was performed to examine the predictors of the learners' behavioral intention to use the LMS, and the constructs of perceived ease of use, perceived usefulness, and perceived satisfaction were tested. The result was significant, $R^{2}=.489, F(3,151)=48.124, p<.001$. Perceived usefulness of the system seemed to have a significant effect on the learners' behavioral intention to use the system (see Table 7).

Table 7

Perceived Ease of Use, Perceived Usefulness, and Perceived Satisfaction as Predictors of Behavioral Intention

\begin{tabular}{lccccc}
\hline Variable & $B$ & $S E$ & $\beta$ & $t$ & $p$ \\
\hline Perceived ease of use & .033 & .080 & .033 & .413 & .680 \\
Perceived usefulness & .585 & .081 & .616 & 7.250 & .000 \\
Perceived satisfaction & .108 & .070 & .106 & 1.549 & .124 \\
\hline
\end{tabular}

Note $. \mathrm{B}=$ unstandardized coefficients, $\mathrm{SE}=$ standard error of the estimate, $\beta=$ standardized coefficients

\section{Discussion and Conclusions}

With this study, the case of a unique educational context was explored through the 3-TUM. On the basis of the findings resulting from the analyses, an explanatory model (see Figure 5) was obtained. In the model, the arrows stand for the direct influence of a construct on another construct or other constructs.

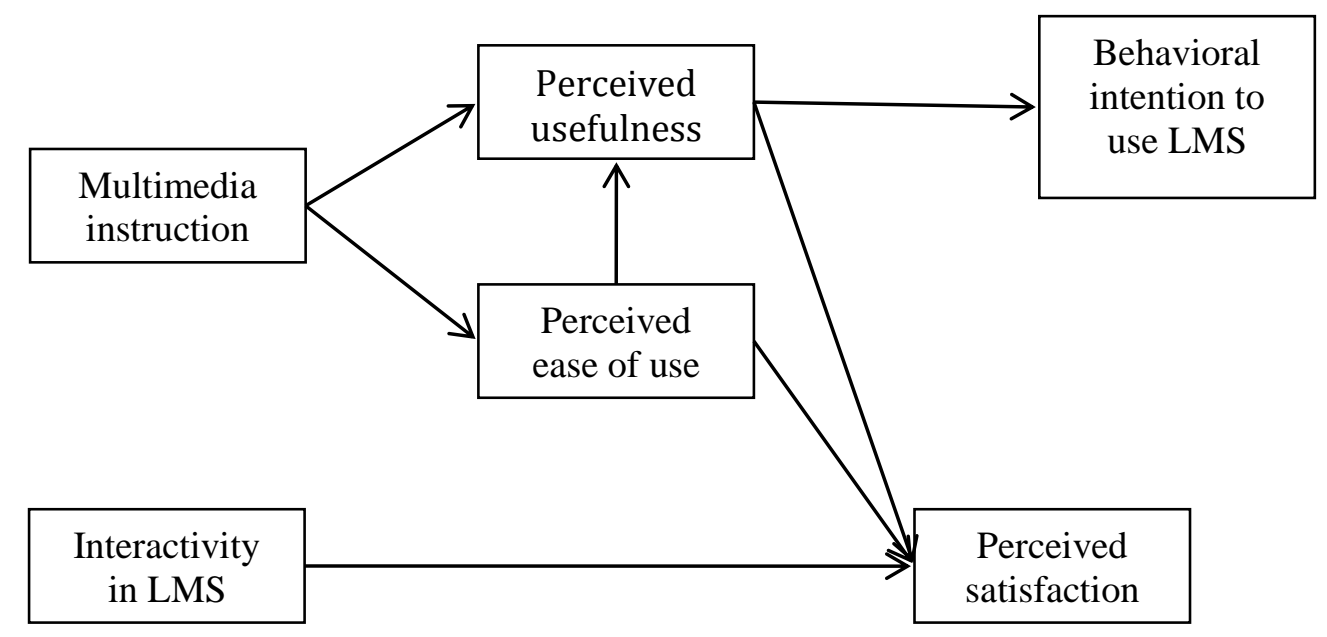

Figure 5. Derived model for students' behavioral intention to use LMS.

Multimedia instruction exerted a direct influence on perceived usefulness and perceived ease of use, which indicated that a system's including instructional multimedia would more probably enable users to think that the system is easy, beneficial, and functional to use for learning purposes. Interactivity exerted a direct influence on perceived satisfaction, which could imply that in the interactivity features of the system would more probably lead to higher level of satisfaction among users. This is consistent with the point proposed by Pituch and Lee (2006) and Damnjanovic et al. (2013). Consistent with Abbad, Morris , 
and Nahlik (2009), there was no strong evidence in our work that the interactivity within the Portal influenced perceived ease of use and perceived usefulness. In this sense, the instructors should be aware of the importance of interactivity for learner satisfaction and thus promote more interactivity with their learners in their lectures through LMSs.

On the other hand, multimedia instructions had a negative effect on perceived satisfaction. It is considered that the students' being directed to check the multimedia instruction within the LMS for any simple question addressed in face-to-face sessions might have affected the learners negatively so that they could feel less satisfied with the system.

Perceived ease of use exerted a direct influence on perceived usefulness, which could mean that when the learners find a system easy to use, they tend to consider the system as beneficial and functional. Similar to Abbad et al. (2009), Cigdem and Topcu (2015) and Davis et al. (1989), it suggests that perceived ease of use has a significant direct effect on perceived usefulness. Thus, system administrators should be aware of the characteristics and needs of learners to make LMS easier to learn and use. However, perceived usefulness and perceived ease of use significantly affected perceived satisfaction. In this regard, learners' perceptions on a system's being easy and beneficial to use would possibly reflect on their satisfaction level with the system. This result reveals a parallel point with some other studies (Cigdem \& Topcu, 2013; Johnson, Hornik, \& Salas, 2008; Liaw, 2008; Šumak et al., 2011), in which it is also asserted that satisfaction is predicted by perceived usefulness.

An important point the model suggested was about the behavioral intention, which was inclined to be directly affected by only perceived usefulness. Accordingly, when the learners believe that a system is useful or practical, they are likely to use that system for learning purposes. This is consistent with the point proposed by Cigdem and Topcu, (2015), Liaw (2008), Sun et al. (2008), and Venkatesh and Morris (2000), yet inconsistent with the point of Park (2009). As only the construct of perceived usefulness had a direct impact on behavioral intention, this finding is considered to somewhat confirm the literature concerning the TAM.

The last interpretation was about the self-efficacy, which was not able to take a position in the model due to its insignificant relationships with the other constructs in the affective and cognitive tier. Although inconsistent with the studies of Abbad et al., (2009), Davis (1989), Park (2009), Venkatesh and Davis (1996), Wang and Wang (2009) and Yuen and Ma (2008), who found that self-efficacy is an important determinant of perceived ease of use, our findings could mean that today's learners enter colleges with greater knowledge and experiences of information and communication technologies than their predecessors did as a result of the continuing spread of computer and Internet across the educational settings. Thereby, learners' self-efficacy is improving day by day. That could be a reason for the assertion that self-efficacy does not seem to be predicting behavioral intention to use the LMS anymore. Similar to our findings, Motaghian, Hassanzadeh, and Moghadam (2013) claimed that self-efficacy had no significant effect on perceived usefulness of LMS as opposed to the findings in Ong, Lai, and Wang (2004), and Park (2009). 
As frequent use of LMSs has increased in many educational institutions, LMS technologies such as video productions have also developed. If we are to satisfy our students with the LMS and increase their engagement with distance learning, we need to use the interactivity and multimedia options of the systems more frequently and improve the interaction facilities within the sytem through frequent feedback on the works of the students and provision of support and responses to their questions. Besides, we need to reconsider and extend the multimedia features of the system so that we could increase the usefulness of the system among the participants. However, it is essential to limit the scope and the length of those features, because they are supposed to be more effective when they are content-based and not too long.

Considering the challenges of distance education in the twenty-first century, it is vital for distance educators to rethink how well they meet the needs of their students and institution as well as to understand possible factors that might ease or hinder the users' acceptance of and engagement with distance learning environments. Such an inquiry is central to the development of the field of practice and theory for which models and concepts within the models appear as important elements.

In this study, an important step was taken to look into the factors that might possibly affect learners' behavioral intention to use the LMS and engagement with distance learning. However, the study has certain limitations. First of all, a kind of self-reported data were gathered from the participants through an online questionnaire. Secondly, regarding the sampling, the current study assessed military college students, and thus the applicability and generalizability of the findings are limited. The third limitation of the study is the gender issue as all of the participants were male due to the characteristics of the military schools in Turkey. If similar studies are replicated in other educational contexts for further investigations, findings could be discussed through a comparative analysis. As a further step, the users of Portal could be interviewed through focus-group or individual interviews in order to get in-depth data about their perceptions on the system. Additionally, their movements in the system could be inspected through a detailed analysis of the logs.

Finally, similar research needs to be conducted in other e-learning practices. As this study focused on the online mode of a blended learning environment, resarchers could carry out similar studies to deal with pure online environments, flipped classrooms, massive open online courses, and so on. Multimedia instruction and interactivity features could also be used in other technology acceptance models.

\section{References}

Abbad, M. M., Morris, D., \& de Nahlik, C. (2009). Looking under the bonnet: factors affecting student adoption of e-learning systems in Jordan. The International Review of Research in Open and Distributed Learning, 1O(2). Retrieved from http://www.irrodl.org/index.php/irrodl/article/view/596 
Ajzen, I. (1991). The theory of planned behavior. Organizational Behavior and Human Decision Processes, 5o, 179-211. doi:10.1016/0749-5978(91)90020-T

Akkoyunlu, B., \& Soylu, M. Y. (2008). A study of student's perceptions in a blended learning environment based on different learning styles. Educational Technology \& Society, 11(1), 183-193. Retrieved from http://www.ifets.info/journals/11 1/13.pdf

Álvarez, A., Martín, M., Fernández-Castro, I., \& Urretavizcaya, M. (2013). Blending traditional teaching methods with learning environments: Experience, cyclical evaluation process and impact with MAgAdI. Computers \& Education, 68, 129-140. doi:10.1016/j.compedu.2013.05.006

Bandura, A. (1977). Self-efficacy: Toward a unifying theory of behavioral change. Psychological Review, 84(2), 191-215. doi:10.1037/0033-295X.84.2.191

Bandura, A. (1986). Social foundations of thought and action: A social cognitive theory. Eaglewood Cliffs, NJ: Prentice Hall.

Bouhnik, D., \& Marcus, T. (2006). Interaction in distance-learning courses. Journal of the American Society Information Science and Technology, 57(3), 299-305. doi:10.1002/asi.20277

Campbell, C. R., \& Swift, C. O. (2006). Perceptions of compressed video distance learning (DL) across location and levels of instruction in business courses. Journal of Education for Business, 81(3), 170-174. doi: 10.3200/JOEB.81.3.170-174

Cigdem, H. (2015). How does self-regulation affect computer-programming achievement in a blended context? Contemporary Educational Technology, 6(1), 19-37. Retrieved from http://www.cedtech.net/articles/61/612.pdf

Cigdem, H., \& Topcu, A. (2013). Students' perception of e-learning in the technical vocational school. Science Journal of Turkish Military Academy, 23(2), 1-19. Retrieved from http://www.kho.edu.tr/akademik/kho bilim dergi/2013 2/1.pdf

Cigdem, H., \& Topcu, A. (2015). Predictors of instructors' behavioral intention to use learning management system: A Turkish vocational college example. Computers in Human Behavior, 52, 22-28. doi:10.1016/j.chb.2015.05.049

Davis, F. D. (1989). Perceived usefulness, perceived ease of use, and user acceptance of information technology. MIS Quarterly, 13(3), 319-340. doi:10.2307/249008

Davis, F. D., Bagozzi, R. P., \& Warshaw, P. R. (1989). User acceptance of computer technology: A comparison of two theoretical models. Management Science, 35, 982-1003. doi: $\underline{10.1287 / \mathrm{mnsc} .35 .8 .982}$ 
Davies, F. D., \& Graff, M. (2005). Performance in e-learning: Online participation and student grades. British Journal of Education Technology, 36, 657-663. doi: 10.1111/j.1467-8535.2005.00542.x

Damnjanovic, V., Jednak, S., \& Mijatovic, I. (2013). Factors affecting the effectiveness and use of Moodle: Students' perception. Interactive Learning Environments, 23(4), 496-514. doi:10.1080/10494820.2013.789062

Dutta, A., Roy, R., \& Seetharaman, P. (2013). Course management system adoption and usage: A process theoretic perspective. Computers in Human Behavior, 29(6), 2535-2545. doi:10.1016/j.chb.2013.06.010

Field, A. P. (2009). Discovering statistics using SPSS: And sex and drugs and rock 'n' roll (3rd ed.). London, UK: Sage.

Geri, N. (2011). If we build it, will they come? Adoption of online video-based distance learning. Interdisciplinary Journal of E-Learning and Learning Objects, 7, 225-234. Retrieved from http://www.ijello.org/Volume7/IJELLOv7p225-234Geri764.pdf

Hernandez, B., Montaner, T., Sese, F. J., \& Urquizu, P. (2011). The role of social motivations in e-learning: How do they affect usage and success of ICT interactive tools? Computers in Human Behavior, 27(6), 2224-2232. doi:10.1016/j.chb.2011.07.001

Islam, A. K. M. N. (2013). Investigating e-learning system usage outcomes in the university context. Computers \& Education, 69, 387-399. doi:10.1016/j.compedu.2013.07.037

Johnson, R. D., Hornik, S., \& Salas, E. (2008). An empirical examination of factors contributing to the creation of successful e-learning environments. International Journal of Human-Computer Studies, 66(5), 356-369. doi:10.1016/j.ijhcs.2007.11.003

Kline, R. B. (2011). Principles and practice of structural equation modeling (3rd ed.) New York, NY: The Guilford Press.

Lee, M. K. O., Cheung, C. M. K., \& Chen, Z. (2005). Acceptance of Internet-based learning medium: The role of extrinsic and intrinsic motivation. Information \& Management, 42, 1095-1104. doi:10.1016/j.im.2003.10.007

Liaw, S.-S. (2004). Considerations for developing constructivist Web-based learning. International Journal of Instructional Media, 31(3), 309-321. Retrieved from http://blog.ncue.edu.tw/sys/lib/read attach.php?id=3093

Liaw, S.-S. (2007). Computers and Internet as a job assisted tool: Based on the three-tier use model approach. Computer in Human Behavior, 23(1), 399-414. doi:10.1016/j.chb.2004.10.018 
Liaw, S.-S. (2008). Investigating students' perceived satisfaction, behavioral intention, and effectiveness of e-learning: A case study of the Blackboard system. Computers \& Education, 51 (2), 864-873. doi:10.1016/j.compedu.2007.09.005

Liaw, S.-S., \& Huang, H.-M. (2007). Developing a collaborative e-learning system based on users' perceptions. Computer supported cooperative work in design III (pp. 751-759). Berlin, Germany: Springer. doi:10.1007/978-3-540-72863-4_76

Liaw, S.-S., \& Huang, H.-M. (2013). Perceived satisfaction, perceived usefulness and interactive learning environments as predictors to self-regulation in e-learning environments. Computers \& Education, 6o(1), 14-24. doi:10.1016/j.compedu.2012.07.015

Melton, B., Graf, J., \& Chopak-Foss, J. (2009). Achievement and satisfaction in blended learning versus traditional general health course designs. International Journal for the Scholarship of Teaching and Learning, 3(1), 26. doi: 10.20429/ijsotl.2009.030126

Michailidou, A., \& Economides, A. (2003). E-learn: Towards a collaborative educational virtual environment. Journal of Information Technology Education, 2, 131-152. Retrieved from http://jite.org/documents/Vol2/v2p131-152-92.pdf

Moore, M. G., \& Kearsley, G. (1996). Distance education: A systems view. Belmonth, CA: Wadsworth.

Motaghian, H., Hassanzadeh, A., \& Moghadam, D. K. (2013). Factors affecting university instructors' adoption of web-based learning systems: Case study of Iran. Computers \& Education, 61, 158167. doi:10.1016/j.compedu.2012.09.016

Motiwalla, L. F. (2007). Mobile learning: A framework and evaluation. Computers \& Education, 49(3), 581-596. doi:10.1016/j.compedu.2005.10.011

Ong, C. S., Lai, J. Y., \& Wang, Y. S. (2004). Factors affecting engineers' acceptance of asynchronous elearning systems in high-tech companies. Information \& Management, 41(6), 795-804. doi:10.1016/j.im.2003.08.012

Paechter, M., Maier, B., \& Macher, D. (2010). Students' expectations of and experiences in e-learning: Their relation to learning achievements and course satisfaction. Computers \& Education, 54(1), 222-229. doi:10.1016/j.compedu.2009.08.005

Park, S. Y. (2009). An analysis of the technology acceptance model in understanding university students' behavioral intention to use e-learning. Educational Technology \& Society, 12(3), 150-162. Retrieved from http://www.ifets.info/journals/12 3/14.pdf

Pituch, K. A., \& Lee, Y. K. (2006). The influence of system characteristics on e-learning use. Computers \& Education, 47, 222-244. doi:10.1016/j.compedu.2004.10.007 
Sahin, I., \& Shelley, M. (2008).Considering students' perceptions: The distance education student satisfaction model. Educational Technology \& Society, 11(3), 216-223. Retrieved from http://www.ifets.info/journals/11 3/15.pdf

Selim, H. M. (2007). Critical success factors for e-learning acceptance: Confirmatory factor Models. Computers \& Education, 49(2), 396-413. doi:10.1016/j.compedu.2005.09.004

Stantchev, V., Colomo-Palacios, R., Soto-Acosta, P., \& Misra, S. (2014). Learning management systems and cloud file hosting services: A study on students' acceptance. Computers in Human Behavior, 31, 612-619. doi:10.1016/j.chb.2013.07.002

Šumak, B., Heričko, M., \& Pušnik, M. (2011). A meta-analysis of e-learning technology acceptance: The role of user types and e-learning technology types. Computers in Human Behavior, 27 (6), 20672077. doi:10.1016/j.chb.2011.08.005

Sun, P. C., Tsai, R. J., Finger, G., Chen, Y. Y., \& Yeh, D. (2008). What drives a successful e-learning? An empirical investigation of the critical factors influencing learner satisfaction. Computers \& Education, 50, 1183-1202. doi:10.1016/j.compedu.2006.11.007

Tabachnick, G. G., \& Fidell, L. S. (2007). Experimental designs using ANOVA. Belmont, CA: Duxbury.

Teo, T. (2011). Factors influencing teachers' intention to use technology: Model development and test. Computers \& Education, 57(4), 2432-2440. doi:10.1016/j.compedu.2011.06.008

Teo, T. (2012) Examining the intention to use technology among preservice teachers: An integration of the Technology Acceptance Model and Theory of Planned Behavior. Interactive Learning Environments, 2O(1), 3-18. doi:10.1080/10494821003714632

Teo, T., Lee, C. B., \& Chai, C. S. (2008). Understanding pre-service teachers' computer attitudes: Applying and extending the technology acceptance model (TAM). Journal of Computer Assisted Learning, 24(2), 128-143. doi: 10.1111/j.1365-2729.2007.00247.x

Venkatesh V., \& Davis F. D. (1996). A model of the antecedents of perceived ease of use: Development and test. Decision Sciences, 27(3), 451-481. doi: 10.1111/j.1540-5915.1996.tboo860.x

Venkatesh, V. \& Davis, F. D. (2000). A theoretical extension of the technology acceptance model: four longitudinal field studies. Management Science, 46, 186-204. doi: 10.1287/mnsc.46.2.186.11926

Venkatesh, V., \& Morris, M. G. (2000). Why don't men ever stop to ask for directions? Gender, social influence, and their role in technology acceptance and usage behavior. MIS Quarterly, 24(1), 115139. doi:10.2307/3250981 
Wang, W., \& Wang, C. (2009). An empirical study of instructor adoption of webbased learning systems. Computers \& Education, 53(3), 761-774. doi:10.1016/j.compedu.2009.02.021

Warshaw, P., \& Davis, F. (1985). Disentangling behavioral intention and behavioral expectation. Journal of Experimental Social Psychology, 21, 213-228. doi:10.1016/0022-1031(85)90017-4

Wieling, M. B., \& Hofman, W. H. A. (2010). The impact of online video lecture recordings and automated feedback on student performance. Computers \& Education, 54(4), 992-998. doi:10.1016/i.compedu.2009.10.002

Yi, M., \& Hwang, Y. (2003). Predicting the use of web-based information systems: Self-efficacy, enjoyment, learning goal orientation, and the technology acceptance model. International Journal of Human-Computer Studies, 59, 431-449. doi:10.1016/S1071-5819(03)00114-9

Yuen, A. H. K., \& Ma, W. W. K. (2008). Exploring teacher acceptance of e-learning technology. AsiaPacific Journal of Teacher Education, 46(3), 229-243. doi:10.1080/13598660802232779

Yukselturk, E., \& Yildirim, Z. (2008). Investigation of interaction, online support, course structure and flexibility as the contributing factors to students' satisfaction in an online certificate program. Educational Technology \& Society, 11(4), 51-65. Retrieved from http://www.ifets.info/journals/11_4/5.pdf

Zhang, S., Zhao, J., \& Tan, W. (2008). Extending TAM for online learning systems: An intrinsic motivation perspective. Tsinghua Science \& Technology, 13(3), 312-317. doi:10.1016/S10070214(08)70050-6

\section{Athabasca University}

